\section{Autoantikörper gegen MAP-2}

W. Stöcker

Euroimmun Medizinische Labordiagnostika AG, Lübeck, Deutschland

Synonym(e) Mikrotubulus-assoziiertes neuronales Protein 2

Englischer Begriff microtubule-associated protein 2

Funktion - Pathophysiologie MAP-2 ist ein Bestandteil des Zytoskeletts neuronaler Zellen. Es kommt ausschließlich in Nervenzellen vor und kann deshalb spezifisch markiert werden, um Ganglienzellen im ZNS oder im vegetativen Nervensystem immunhistochemisch zu identifizieren und zum Beispiel von (GFAP-positiven) Gliazellen zu unterscheiden (,glial fibrillary acidic protein“).

Untersuchungsmaterial Serum, Plasma.

Probenstabilität Autoantikörper sind bei $+4{ }^{\circ} \mathrm{C}$ bis zu 2 Wochen lang beständig, bei $-20^{\circ} \mathrm{C}$ über Monate und Jahre hinweg.

Analytik Indirekte Immunfluoreszenz ( $\triangleright$ Immunfluoreszenz, indirekte) mit Gewebeschnitten von Großhirn, Kleinhirn, Rü- ckenmark, Magen, Darm oder mit rekombinant exprimiertem MAP-2-Antigen in HEK-293-Zellen als Antigensubstraten. Alternativ \Enzyme-linked Immunosorbent assay- und \ Immunblot-Verfahren ( $\triangleright$ Western blot: $210 \mathrm{kDa}$ ).

\section{Referenzbereich - Erwachsene Negativ.}

\section{Referenzbereich - Kinder Negativ.}

Indikation Systemischer Lupus erythematodes mit Beteiligung des Zentralnervensystems (,neuropsychiatric SLE“), Prävalenz um $77 \%$ (alle von 100 SLE-Fällen zusammen: nur $17 \%)$.

Interpretation Eingeschränkte Krankheitsspezifität, die Antikörper sollen auch bei alkoholischer Leberkrankheit, Virushepatitis und primär biliärer Cholangitis auftreten.

\section{Literatur}

Komatsu M, Goto M, Yamamoto A, Toyoshima I, Masamune O (1990) A new autoantibody, anti-210 $\mathrm{kDa}$ microtubule associated protein antibody, detected in the serum of patients with various liver diseases and SLE. Nihon Shokakibyo Gakkai Zasshi 87:2451-2456

Williams RC Jr, Sugiura K, Tan EM (2004) Antibodies to microtubuleassociated protein 2 in patients with neuropsychiatric systemic lupus erythematosus. Arthritis Rheum 50:1239-1247 